\title{
The T-cell response to lipid antigens of Mycobacterium tuberculosis
}

\section{Gennaro De Libero ${ }^{1,2}{ }^{*}$ and Lucia Mori ${ }^{1}$}

1 Singapore Immunology Network, Agency for Science, Technology and Research (A*STAR), Singapore, Singapore

${ }^{2}$ Experimental Immunology, Department of Biomedicine, University Hospital Basel, Basel, Switzerland

\section{Edited by:}

Juraj Ivanyi, Kings College London, UK

\section{Reviewed by:}

Roberto Nisini, Istituto Superiore di Sanità, Italy

Dirk Michael Zajonc, La Jolla Institute for Allergy and Immunology, USA

\section{*Correspondence:}

Gennaro De Libero, 8A Biomedical Grove, Immunos, 138648 Singapore e-mail: gennaro_delibero@immunol. a-star.edu.sg
T-cells recognize lipid antigens presented by dedicated antigen-presenting molecules that belong to the CD1 family. This review discusses the structural properties of CD1 molecules, the nature of mycobacterial lipid antigens, and the phenotypic and functional properties of T-cells recognizing mycobacterial lipids. In humans, the five CD1 genes encode structurally similar glycoproteins that recycle in and thus survey different cellular endosomal compartments. The structure of the CD1-lipid-binding pockets, their mode of intracellular recycling and the type of CD1-expressing antigen-presenting cells all contribute to diversify lipid immunogenicity and presentation to T-cells. Mycobacteria produce a large variety of lipids, which form stable complexes with CD1 molecules and stimulate specific T-cells. The structures of antigenic lipids may be greatly different from each other and each lipid may induce unique T-cells capable of discriminating small lipid structural changes. The important functions of some lipid antigens within mycobacterial cells prevent the generation of negative mutants capable of escaping this type of immune response. T-cells specific for lipid antigens are stimulated in tuberculosis and exert protective functions. The mechanisms of antigen recognition, the type of effector functions and the mode of lipid-specific T-cell priming are discussed, emphasizing recent evidence of the roles of lipid-specific T-cells in tuberculosis.

Keywords: CD1, lipid antigens, tuberculosis, T-cells, antigen presentation

\section{INTRODUCTION}

The discovery that $\mathrm{T}$ lymphocytes recognize lipid molecules as antigens (1) was a breakthrough in cellular immunology that opened unexpected horizons in the field of immune response to microbes, to cancer cells, and in autoimmunity.

Despite main structural differences with peptide antigens, lipid antigens are presented to $\mathrm{T}$-cells following general rules that closely resemble those implicated in the presentation of peptide antigens. Indeed, only lipids forming stable complexes with dedicated antigen-presenting molecules, which belong to the $\mathrm{CD} 1$ protein family (2), are capable of interacting with the T-cell receptor (TCR) and may induce the activation of specific T-cells.

Many different types of lipids behave as antigens capable of stimulating specific T-cells and Mycobacterium tuberculosis is the bacterium with the largest number of antigenic lipids identified so far. Mycobacteria are characterized by a complex cellular envelope composed of a variety of unique lipids (3), which have important functions in survival of mycobacterial bacilli (4). Envelope lipids are also implicated in tissue-specific replication (5) and controlled penetration of engulfing cells (6) and in escaping immune response with different mechanisms (7). Therefore, Mycobacteria are reluctant in changing the lipid composition of their envelope. Mycobacterial lipids, glycolipids, and lipopeptides may bind to and form stable complexes with different CD1 molecules, and may interact with specific TCR.

The generation of stable CD1-lipid antigen complexes mostly occurs within the infected cell and follows a series of well coordinated events. These include the transport of lipid antigens by lipid chaperones in cellular membranes and endosomal compartments, the extraction of lipids from membranes, their processing, and subsequent insertion in the hydrophobic pockets of CD1 molecules. Stable CD1-lipid complexes are then routed to the plasma membrane where they become available for T-cell recognition (8).

Mycobacteria have evolved a series of tactics to interfere with lipid antigen presentation, showing the surprising capacity of inhibiting and hijacking different protective immune mechanisms. The existence of these evasion strategies is the indirect evidence that lipid-specific immune response represents an important mechanism of defense in tuberculosis. How lipid-specific T-cells participate in controlling mycobacterial infections is an important field of investigation in many laboratories that is providing new information on protective immune mechanisms and is suggesting novel approaches to vaccine development.

This chapter describes the nature, structure, and function of mycobacterial lipid antigens, the mechanisms of their recognition by T-cells, the biological properties of $\mathrm{CD} 1$ antigen-presenting molecules and the rules that govern presentation of lipids to Tcells. The relevance of lipid-specific T-cells in tuberculosis is also discussed.

\section{CD1 ANTIGEN-PRESENTING MOLECULES}

In humans five genes encode different $\mathrm{CD} 1$ isoforms, which are classified into three families (group 1, 2, and 3). CD1a, b, and c molecules belong to the group 1 family, whereas CD1d and CD1e are the only members of group 2 and 3, respectively. The separation into three families follows important structural differences, 
cellular and tissue distribution of each CD1 protein. CD1a, b, and c are expressed on CD4, CD8 double positive thymocytes, and on peripheral antigen-presenting cells (APC), including dendritic cells (DC), monocytes, and a subset of B cells. Each of these molecules can be uniquely expressed. For example, CD1a, but not CD1b and $c$ are expressed by Langerhans cells in the skin and represent a marker distinguishing this cell population. CD1b is expressed by a population of monocytes and is upregulated during differentiation into DC. CD1c is expressed on a large fraction of human B cells. CD1d is instead more extensively expressed on both hematopoietic and non-hematopoietic cells.

CD1e is the only CD1 protein that is not expressed on the plasma membrane and remains confined within the Golgi complex and late endosomes/lysosomes. All CD1 molecules are expressed by professional APC such as DC.

The structures of all CD1 molecules have been solved and showed important differences that illustrate their unique antigenbinding capacities.

\section{STRUCTURE OF CD1 MOLECULES AND REPERTOIRE OF PRESENTED LIPID ANTIGENS}

CD1 molecules have structures similar to those of MHC class I molecules. They are glycoproteins composed of a heavy chain noncovalently associated with $\beta 2$-microglobulin. The heavy chain is made of three domains. The $\alpha 1$ and $\alpha 2$ domains, which assemble together in the membrane distal part of the molecule, are characterized by two anti-parallel $\alpha$ helices positioned above a $\beta$ sheet plate. The $\alpha 3$ domain instead is membrane-proximal and associates with $\beta 2$-microglobulin. It also continues with the transmembrane domain and a short intracytoplasmic tail. Each CD1 molecule shows a portal located in between the $\alpha 1$ and $\alpha 2$ helices, which allows access to two to four pockets. The pockets are surrounded by hydrophobic amino acids, thus representing ideal places to allocate the apolar alkyl chains of lipid antigens.

\section{CD1a}

Each CD1 molecule shows unique structural features.

CD1a has one portal located between the two $\alpha$ helices, which is connected with two pockets, called $\mathrm{A}^{\prime}$ and $\mathrm{F}^{\prime}$ (a nomenclature similar to that of MHC molecules). Around the portal a few charged amino acids stabilize and properly orient the antigen headgroup for TCR recognition. The $\mathrm{F}^{\prime}$ pocket has an incomplete roof thus being partially open on the surface of CD1a. The mode of lipidbinding of CDla is unique, since the open $\mathrm{F}^{\prime}$ pocket permits ready insertion and replacement of lipid antigens. This feature optimally complements another unique characteristics of CD1a, i.e., its recycling through early endosomal stations $(9,10)$. Early endosomal compartments are slightly acidic environments that do not induce main conformational changes to the structure of recycling proteins. In addition, lipid transfer proteins that facilitate lipid antigen loading on CD1 molecules are localized in other endosomal compartments. Therefore, an open $\mathrm{F}^{\prime}$ pocket seems a natural evolution of CD1a to facilitate otherwise unfavorable conditions for loading of lipid antigens.

The co-crystal of CD1a with lipid antigens have also provided important information on another consequence of the unique open $\mathrm{F}^{\prime}$ pocket structure.
The CD1a-sulfatide structure revealed that the sphingosine occupies the $\mathrm{A}^{\prime}$ pocket whereas the fatty acid chain protrudes in the interface of the $\mathrm{A}^{\prime}$ and $\mathrm{F}^{\prime}$ pockets. The headgroup of sulfatide, made by a galactose and a sulfate is anchored in the $\mathrm{A}^{\prime}-\mathrm{F}^{\prime}$ junction and partially occupies the upper part of the $\mathrm{F}^{\prime}$ pocket in a position ideally suited for TCR recognition (11).

The crystal structure of CD1a with lipopeptide dideoxymycobactin (DDM) instead showed that while the single alkyl chain was inserted deep within the $\mathrm{A}^{\prime}$ pocket, the two peptidic moieties of the antigen were lying partially in the $\mathrm{F}^{\prime}$ pocket and at the surface of CDla, an optimal position for recognition by the TCR (12).

\section{MYCOBACTERIAL LIPID ANTIGENS PRESENTED BY CD1a}

The overall size of CD1a grove is limited to $1350 \AA^{3}$, thus precluding binding of lipid antigens of large size. So far, only DDM has been identified as mycobacterial antigen presented by CD1a (13).

Dideoxymycobactin is the precursor of mycobactin, a siderophore with iron scavenging properties. The structure of DDM shows a complex head group made of unusual amino acids synthesized by non-ribosomal mycobacterial enzymes. The lysine of headgroup is linked to a single alkyl chain, which is 20 carbons long. One clone specific for CD1a-DDM was isolated and when it was tested the length and saturation of the DDM alkyl chain appeared very important for T-cell stimulation. This behavior was fully explained by the structural resolution of the CD1a-DDM complex, which showed a deep insertion of the acyl chain in the CD1a $\mathrm{A}^{\prime}$ pocket. As this pocket is closed at one end, the insertion of too short or too long acyl chains determines a different positioning of the peptidic residues, thus directly influencing the interaction with the TCR. This mode of binding led the authors to discuss a role as a ruler of the $\mathrm{A}^{\prime}$ CD1a pocket (12). During their intracellular growth, mycobacteria increase mycobactin synthesis to increase their capacity of iron capture. Thus presentation of DDM may be an efficient mechanism to identify cells harboring living mycobacteria.

CD1b

The molecule CD1b is expressed by activated monocytes and DC. CD1b presents most of the identified mycobacterial antigens and follows unique recycling and lipid loading rules. Within the group 1 CD1 family, CD1b has the largest pocket $\left(\sim 2200 \AA^{3}\right)$ and is made by four interconnected pockets, which confer unique lipid antigenbinding properties. A large portal is located between the two $\alpha$ helices that is connected with the $\mathrm{A}^{\prime}, \mathrm{C}^{\prime}$, and $\mathrm{F}^{\prime}$ pockets. The $\mathrm{A}^{\prime}$ pocket continues into the $\mathrm{F}^{\prime}$ pocket through a tunnel called $\mathrm{T}^{\prime}$ pocket. The combination of the four pockets with the large size, allows CD1b to bind lipid antigens with very long alkyl chains, such as the mycobacterial mycolyl chains that can reach a length of 80 carbons. The structure of CD1b has been solved thus revealing how CD1b can accommodate either very long or short lipid antigens (14-17). Mycolic acid (MA), an antigen with long alkyl chain that can contain up to 80 carbons occupies the $\mathrm{A}^{\prime}, \mathrm{T}^{\prime}$, and $\mathrm{F}^{\prime}$ pockets, whereas the mycobacterial diacylated sulfoglycolipids (SGL) occupy the $\mathrm{A}^{\prime}$ and $\mathrm{C}^{\prime}$ pockets with their two alkyl chains. This flexibility in lipid-binding raised the question of why the CD1b $\mathrm{T}^{\prime}$ pocket does not collapse when antigens with short alkyl chains are bound. The reason for this stability was found when a soluble 
CD1b molecule produced in eukaryotic cells and physiologically refolded in vivo was crystallized. This molecule showed the presence of different spacers within the $\mathrm{T}^{\prime}$ pocket, thus representing a filling lipid preventing the collapse of the molecule (18).

\section{MYCOBACTERIAL LIPID ANTIGENS PRESENTED BY CD1b}

Mycolic acids were the first antigens, which were identified as lipids capable of stimulating specific T-cells (19). These long and highly hydrophobic lipids represent very important components of the cell wall of several bacteria, including Mycobacteria, Corynebacteria, and Nocardia. MA are unique fatty acids of high-molecularweight, with $\alpha$-alkyl, $\beta$-hydroxyl groups. They may be present as such or as bound esters of sugars like arabinogalactan and trehalose. Activation assays using different types of MA, showed that the hydroxyl and carboxyl groups may represent important structural features sensed by T-cells (19).

Mycolic acid may also be considered as scaffold molecules that form stimulatory antigen when attached to other molecules. For example, glucose monomycolate (GMM) is capable of stimulating specific T-cells (20). In GMM, a glucose residue is attached to MA and is critical for T-cell recognition as the stereoisomers mannose- or galactose-monomycolate are not or poorly stimulatory. T-cells also discriminate the type of glycosidic bond, as GMM with glucose bound with 6-hydroxyl to MA is stimulatory, whereas glucose-3-monomycolate is not stimulatory (21).

Another antigen with modified MA is glycerol monomycolate (GroMM) (22) that is made of a glycerol moiety attached to a MA and is also produced by Mycobacteria, Corynebacteria, and Nocardia. The glycerol hydroxyl moiety and the fatty acid length of GroMM influence T-cell response. MA-related lipids are presented only by $\mathrm{CD} 1 \mathrm{~b}$ as this is the only $\mathrm{CD} 1$ molecule with an open $\mathrm{T}^{\prime}$ pocket allowing the insertion of long fatty acids.

A second family of lipid antigens presented by CD1b is those sharing a phosphatidyl-myo-inositol (PI). Phosphatidylinositol mannoside (PIM) and lipoarabinomannan (LAM) are two lipid antigens presented by CD1b (23). LAM and PIM share a core region, where the mannoses linked to PI are the stimulatory antigens. LAM contains a terminal part with many arabinoses in some instances capped with mannoses. Lipomannan (LM), which is similar to LAM, but does not contain arabinose, can also stimulate specific T-cells (23). T-cells discriminate lipoglycans made in different bacteria. T-cells recognizing LAM from Mycobacterium leprae, do not recognize LAM from M. tuberculosis (23). These LAM differ in the number and branching points of mannoses present in the core that are probably involved in interacting with the TCR.

All lipoglycans are too big to allocate within the CD1b pockets and interact with T-cells. They require internalization and processing in late endosomes (24). $\mathrm{PIM}_{6}$, which is the hexamannosylated form of PIM, also requires processing with shortening of the hexamannoses in order to stimulate specific T-cells (25). Another aspect that is not clear yet is whether these antigens also require processing by lipases. Indeed naturally occurring PIM is characterized by four alkyl chains and they need ad hoc cleavage before forming stable complexes with CD1b (our unpublished data).

A third family of CD1b-presented lipid antigens is that of SGL (26). SGL are localized in the outer part of cell envelope and their abundance was associated with strain virulence (27), although mutant strains revealed that sulfolipid deficiency does not significantly affect the replication, persistence, and pathogenicity of $M$. tuberculosis $\mathrm{H} 37 \mathrm{Rv}$ in mice and guinea pigs or in cultured macrophages (28). SGL contain a trehalose $2^{\prime}$ sulfate core, acylated by two to four fatty acids. This antigen isolated from virulent mycobacteria strains proved to a be a mixture of structurally related diacylated SGL $\left(\mathrm{Ac}_{2} \mathrm{SGL}\right)$ containing hydroxyphtioceranoic and palmitic or stearic acid, both linked to the glucose without the sulfate in the trehalose. The tri- and tetra-acylated forms were not immunogenic, thus revealing that APC do not have the proper lipase apparatus to digest these forms and generate the diacylated immunogenic forms. Removal of the sulfate group completely abolished Tcell activation (26), suggesting that the fine antigen specificity of the TCR is also influenced by the strong negative charges of sulfate.

The structure of CD1b-SGL complex has been solved and showed a unique mode of interaction of this lipid antigen with the CD1b (17). Comparison of the CD1b crystals with and without SGL showed that upon antigen-binding, the endogenous spacers of CD1b, which consist of a mixture of diradylglycerols, move considerably within the lipid-binding groove. Spacer displacement was accompanied by $\mathrm{F}^{\prime}$ pocket closure and an extensive rearrangement of residues exposed to T-cell receptors. Such structural reorganization resulted in reduction of the $\mathrm{A}^{\prime}$ pocket capacity and led to incomplete embedding of the methyl-ramified portion of the phthioceranoyl chain of the antigen, explaining why such hydrophobic motifs are critical for T-cell receptor recognition. Mutagenesis experiments supported the functional importance of the observed structural alterations for T-cell stimulation. Thus, $\mathrm{CD} 1 \mathrm{~b}$ is a very plastic molecule, capable of important structural rearrangements that combine spacer repositioning and ligandinduced conformational changes. Both these changes endow $\mathrm{CD} 1 \mathrm{~b}$ with the capacity to present a broad range of structurally diverse antigens and to focus the TCR only on the antigen-filled CD1b molecules.

\section{CD1c}

The CD1c molecule is characterized by unique features that contribute to the important biological features of this $\mathrm{CD} 1$ isotype.

The central portal located in between the two alpha helices allows protrusion of the hydrophilic moiety of bound antigen, which is presumably involved also in contacting the TCR. This portal is connected with the $\mathrm{A}^{\prime}$ and $\mathrm{F}^{\prime}$ pockets. The $\mathrm{A}^{\prime}$ pocket may accommodate the alkyl chain of bound antigen (29). The $\mathrm{A}^{\prime}$ pocket is open to the external part of $\mathrm{CD} 1 \mathrm{c}$ with an exit portal located underneath the $\alpha 1$ helix. Interestingly, the $\mathrm{F}^{\prime}$ pocket of $\mathrm{CD} 1 \mathrm{c}$ showed an open cavity, which is similar to the antigenbinding groove of MHC-peptide-binding molecules and in some respects to the $\mathrm{F}^{\prime}$ pocket of $\mathrm{CD1}$. The $\mathrm{F}^{\prime}$ pocket is also open to the exterior with a second portal called $\mathrm{E}^{\prime}$. Whether these additional portals facilitate binding of very long alkyl chains, remains unclear, although this type of antigen interaction is energetically unfavorable.

$\mathrm{CD} 1 \mathrm{c}$ is also characterized by a unique type of intracellular recycling. It may recycle in deep endosomal compartments, 
where low $\mathrm{pH}$ may facilitate partial CD1 unfolding and antigen loading. Furthermore, in these compartments dedicated lipid antigen-binding proteins (LBP) are present, which behave as lipid chaperones and are involved in lipid antigen-binding, transport, and loading on CD1 molecules. This mode of antigen loading resembles that of lipids on $\mathrm{CD} 1 \mathrm{~b}$ and $\mathrm{CD} 1 \mathrm{~d}$. In addition, some CD1c molecules recycle through the early endosomal compartments, where the most acidic $\mathrm{pH}$ is 6.5 and probably no LBP are present. In this cellular compartment, the partially open structure of the $\mathrm{F}^{\prime}$ pocket might facilitate antigen exchange and binding.

\section{MYCOBACTERIAL LIPID ANTIGENS PRESENTED BY CD1c}

Both the unique portals and structure of the $\mathrm{F}^{\prime}$ pocket explain the promiscuous antigen-binding behavior of CD1c. This molecule may present lipid antigens containing one alkyl chain (30), two alkyl chains (31), or lipopeptides formed by one alkyl chain linked to a short peptide (32). Furthermore, CD1c stimulates a population of T-cells expressing the gamma and delta chains of the TCR $($ TCR $\gamma \delta)(33,34)$. As the described CD1c-restricted TCR $\gamma \delta$ cells are autoreactive, it is very probable that CD1c presents a self-antigen, which remains unknown.

Recently, we have identified the novel self lipid methyllysophosphatidic acids (mLPA), not described before, which accumulates in myeloid and lymphoid leukemia cells and induces a CD1c-restricted response directed against these human leukemias (35). mLPA-specific T-cells efficiently kill CD1c ${ }^{+}$acute leukemia cells, and protect immunodeficient mice against $\mathrm{CD}^{+} \mathrm{c}^{+}$human leukemia cells and poorly recognize non-transformed CD1cexpressing cells. Whether similar types of lipids are produced by mycobacteria or accumulate in infected cells during mycobacterial infection and induce CD1-restricted T-cell responses is matter of current investigation.

Mannosyl $\beta$-1-phosphomycoketides (MPM) were the first CD1c-restricted lipid antigens (30). MPM contain a single fully saturated alkyl chain with methyl branches at every fourth carbon. MPM are synthesized by Mycobacteria infecting human cells, including M. tuberculosis, BCG, and Mycobacterium avium, and not by rapidly growing saprophytes, including Mycobacterium phlei, Mycobacterium fallax, and Mycobacterium smegmatis (36). The structure of MPM is similar to that of phosphodolichols that in mammalian cells function as carbohydrate donors in glycan synthesis. However, differently from phosphodolichols they are not synthesized through an isoprenoid-independent pathway. Instead, the synthesis of MPM is accomplished by the enzyme Pks12 and requires the sequential condensation of malonate and methylmalonate units. Probably, these polyketides are involved in bacterial intracellular growth and in mannose transmembrane transport, according to their structural similarity with eukaryotic phosphodolichols. As found with other glycolipid-specific T-cells, also MPM-specific T-cell recognition is sensitive to structural changes in the hydrophilic and hydrophobic parts of MPM. Antigen recognition occurs when glucose and not mannose is present. Furthermore, the saturated $\alpha$-prenyl like unit and the length of the prenyl chain are important for recognition. Moreover, variation in the number, length, and saturation of alkyl chains, and the precise chemistry and chirality of the lipid head group, also exert dominant influences on antigenicity $(30,36,37)$, probably by affecting the mode of CD1 binding and interaction with the TCR (38).

\section{CD1d}

Like other CD1 molecules, also CD1d contains antigen-binding pockets, which are much deeper than the groove of peptidebinding MHC molecules. The two pockets are constituted by a non-polar or hydrophobic surface. The pockets converge in a portal open on the surface of CD1d and located in between the two anti-parallel helices. A series of TCR-CD1d-lipid antigen cocrystals have shown the importance of the polar antigen residues, which provide minimal but essential interactions with the TCR (39-42).

The $\mathrm{A}^{\prime}$ pocket of CD1d is closed and allows the insertion of alkyl chains with a defined length. In the presence of lipid antigens with too short alkyl chains, small fatty acids may also be present, which contribute to filling the entire $\mathrm{A}^{\prime}$ pocket probably behaving as rulers preventing CD1d collapse (43).

CD1d is expressed on mostly all hematopoietic cells. It is also present on the surface of gut epithelial cells, adipocytes, and some keratinocytes. Most of the cells retain a large fraction of properly assembled CD1d in late endosomes and lysosomes, in a manner similar to that of MHC class II molecules. Upon synthesis, CD1d rapidly traffics to the plasma membrane and then initiates a fast intracellular recycling. A fraction of CD1d molecules is assembled together with the invariant chain that promotes a direct traffic to late endosomes (44). The mode of intracellular trafficking of CD1d is dependent on the unique intracytoplasmic tail that facilitates the interaction with the AP3 proteins (45). Indeed, this association is necessary to properly load lipid antigens intracellularly (46).

Many microorganisms modulate surface CD1d, including $M$. tuberculosis. Several studies have outlines different modulation capabilities according to the type of cell, the triggered surface receptor, and the possible involvement of soluble factors. While several viruses, including vaccinia, herpes simplex, hepatitis, and lymphocytic choriomeningitis viruses decrease CD1d expression in myeloid cells (47-49), infections with Salmonella typhimurium or E. coli increase the plasma membrane display of CD1d (50). $M$. tuberculosis infection or mycobacterial lipids also upregulate CD1d on bone-marrow-derived macrophages (51). Instead M. tuberculosis infection prevents the upregulation of CD1d in monocytes that differentiate to DC $(52,53)$.

\section{MYCOBACTERIAL LIPID ANTIGENS PRESENTED BY CD1d}

CD1d-restricted T-cells are classified in two major groups. The most widely investigated are invariant natural killer $\mathrm{T}$ (iNKT) cells, which express an invariant human V $\alpha 24 \mathrm{~J} \alpha 18$ or mouse V $\alpha 14$ J $\alpha 18$ TCR chain. These cells recognize with high affinity the $\alpha$-galactosylceramide ( $\alpha$ GalCer) lipid extracted from the marine sponge Agelas mauritianus (54). iNKT cells are highly conserved in many species, thus suggesting that they exert important immunological functions conserved during evolution. iNKT cells also recognize other non-microbial antigens, including phosphatidylinositol (PI), phosphatidylglycerol (PG), and phosphatidylethanolamine (PE), although with a weak affinity compared to the strong agonist $\alpha$ GalCer (55). Lysophosphatidylcholine, a lipid generated by lipid-dependent 
signaling pathways, may also stimulate iNKT cells (56). Other CD1d-presented antigens are the ether-bonded mono-alkyl glycerophosphates that together with the precursors and degradation products of plasmalogens are required for the proper selection and maturation of iNKT cells in the thymus (57).

Very initial studies suggested that a tetramannosylated PIM form $\left(\mathrm{PIM}_{4}\right)$ present in a fraction of lipids purified from Mycobacterium bovis BCG was a potential CD1d-presented iNKT cell antigen (58). These findings have not been confirmed in subsequent studies and the potential role of $\mathrm{PIM}_{4}$ as CD1d-presented antigen to iNKT cells still awaits confirmation. While CD1d mycobacterial antigens have not been identified so far, other bacteria produce strong iNKT stimulatory lipids, including the glycolipids with diacylglycerol moieties of Borrelia burgdorferi and Streptococcus pneumoniae $(59,60)$, and the glycosphingolipids present in the cell walls of bacteria belonging to the genera Sphingomonas and Novosphingobium (61). Surface glycophospholipids of the protozoal parasites Leishmania species are also iNKT stimulatory antigens (62). iNKT-deficient mice are more susceptible to Leishmania infection, indicating that iNKT cells have important functions in protection. However, it is still unknown how Leishmania lipophosphoglycan (LPG) stimulate these T-cells. While LPG binds to CD1d, CD1d-LPG complexes do not stimulate iNKT cells. DC pulsed with LPG can induce IFN $\gamma$ release by iNKT cells, suggesting that LPG stimulates the production of endogenous lipid ligands, which in turn activate iNKT cells. This is not a remote possibility, since bacterial infections may induce important changes in the lipid metabolism of infected cells. This, in turn, may induce accumulation of endogenous lipids that stimulate $\mathrm{T}$-cells restricted by either group 1 or group 2 CD1 molecules (63-65).

A second group of CD1d-restricted T-cells utilized noninvariant TCR and resemble other T-cells involved in classical adaptive immune responses. These T-cells recognize PG, diphosphatidylglycerol (DPG or cardiolipin), and PI from $M$. tuberculosis or Corynebacterium glutamicum as microbial antigens (66). Importantly, the same lipid molecules are present also in mammalian cells and thus they represent self-antigens. Thereby, the increased availability of these self-antigens within APC might also contribute to the activation of CD1d-restricted T-cells cross-reactive with microbial antigens.

\section{CD1e}

CD1e is a unique type of CD1 molecule as it remains intracellular and therefore cannot be considered a bona fide antigen-presenting molecule (67). CD1e is mostly expressed by DC where it accumulates in the Golgi stack of immature cells as pre-protein (68). Upon maturation, CD1e is ubiquitinated (69) and traffics to the lysosomes where it is cleaved in two places. In the amino-terminal region a propeptide is cleaved, that is responsible for the assembly of CD1e with $\beta 2$-microglobulin. Upon its removal CD1e becomes fully active (70). CD1e is also cleaved in its membrane-proximal region, thus becoming a mature soluble protein. CD1e is apparently not secreted and does not accumulate in other intracellular compartments. These features make CD1e similar to the HLADM and HLA-DO molecules, which are also not expressed on the plasma membrane of APC. The acid pH of lysosomes promotes a partial alteration of CDle structure together with the binding of lipid antigens through increased hydrophobic and ionic interactions (71).

The crystal structure of CD1e revealed a groove less intricate than in other CD1 proteins, with a significantly wider portal. The water-exposed CD1e groove probably allows loose contacts with lipid antigens as supported by the finding that lipid association and dissociation processes were faster with CD1e than with CD1b (72).

All these structural features support the function of CD1e as a LBP with the exquisite capability of facilitating lipid antigen presentation by other CD1 molecules. Indeed, CD1e mediates in vitro the transfer of lipids to CD1b and the displacement of lipids from stable CD1b-antigen complexes (72). CD1e is also required for the proper processing of complex mycobacterial lipid antigens such as the $\mathrm{PIM}_{6}$ molecules. In the presence of CD1e, $\mathrm{PIM}_{6}$ is cleaved to $\mathrm{PIM}_{2}$ and is loaded on CD1b (25). CD1e may also positively or negatively affect lipid presentation by CD1b, CD1c, and CD1d (73). This effect is achieved by a rapid formation of CD1-lipid complexes in the presence of CD1e, and also by an accelerated turnover of formed CD1-lipid antigen complexes. These effects maximize and temporally narrow CD1-restricted responses. CD1e is therefore an important modulator of both group 1 and group 2 CD1-restricted responses influencing the lipid antigen availability as well as the generation and persistence of CD1-lipid complexes.

\section{T-CELLS RECOGNIZING MYCOBACTERIAL LIPID ANTIGENS}

T-cells stimulated by lipid antigens are divided into two categories according to their functional behavior and mechanism of antigen recognition. T-cells restricted by group $1 \mathrm{CD} 1$ molecules and type II NKT cells are considered as arm of adaptive T-cell responses, while CD1d-restricted type II NKT or iNKT cells are considered as the typical representative of innate T-cell responses.

Lipid-specific T-cells that are restricted by group 1 CD1 molecules are present as naïve T-cells and expand after encountering the antigen, mostly during mycobacterial infections or BCG vaccination (26). They expand and may also differentiate into classical memory T-cells (74). These studies have been performed using human samples, as small rodents do not express group 1 CD1 molecules. Upon antigen recognition, lipid-specific T-cells release pro-inflammatory cytokines and may also kill intracellular Mycobacteria, thus participating in host protection (26). They also induce maturation of DC (75), thus facilitating priming of other mycobacteria-specific T-cells.

The TCR repertoire of lipid-specific T-cells is polymorphic and there is no evidence of unique TCR V genes imposing the recognition of antigens presented by CD1a, CD1b, or CD1c. There is also no evidence that type II NKT cells utilize a restricted TCR repertoire. Recently, using CD1b tetramers loaded with GMM, a rare population of T-cells was identified, which uses a nearly invariant TCR (76). These T-cells were defined as mycolyl lipidreactive (GEM) cells. The TCR of these GMM-specific and CD1brestricted T-cells is constituted by a TRAV1.2 gene rearranged to TRAJ19 segment. Furthermore, these T-cells showed a strong bias for usage of TRB6-2 gene and high affinity for the CD1b-GMM complex. The analysis of nucleotides in the CDR3 of the $\mathrm{V} \alpha$ chain showed that similar CDR3 amino acids were derived from different patterns of exonucleolytic trimming of the $\mathrm{V}$ and J regions, suggesting an antigen recognition-induced mechanism driving the 
expansion of these cells. This conclusion was also supported by the finding of identical nucleotide sequences in GMM-specific T-cells. In addition, the same sequences were found several times in the same donors, indicating in vivo expansion of GEM T-cells. A second study also showed that CD1b-GMM tetramers may identify another population of T-cells, using the TRAV17 and TRBV4-1 genes, which is present in several donors, has intermediate affinity for the CD1b-GMM complexes and shows biased but different CDR3 motifs (77). Whether this second population is expanded in donors with active or latent tuberculosis remains to be defined.

The identification of lipid-specific T-cells has made an incredible technical jump by using the tetrameric forms of soluble CD1 molecules loaded with lipid antigens. In addition to the CD1b tetramers that have been discussed above, also CD1c (78) tetramers have been generated. With the use of these tetramers it was possible to identify a population of CD1c-restricted and mycoketidespecific T-cells that use a polyclonal TCR repertoire. The identification of CD1-restricted T-cells using antigen-loaded CD1 tetramers has important implications, since detection of lipid-specific T-cells might represent a novel approach to monitor the T-cell response in patients with active or latent forms of tuberculosis.

An important set of data indicates that group 1 CD1-restricted T-cells have important functions in animal models and in humans.

Immunization of guinea pigs (Cavia porcellus), a species expressing multiple CD1b and CD1c gene orthologs, induces strong proliferative and cytotoxic responses restricted by CD1b and $\operatorname{CD1c}(79,80)$ and immunization with total M. tuberculosis lipids induced a significant reduction of lung lesions (81).

Cattle (Bos taurus) are sensitive to natural infection with M. bovis, causing bovine tuberculosis that shares many clinical and pathological characteristics with human tuberculosis. Polyclonal T-cells isolated from naturally infected animals showed specific response to challenge with lipids from $M$. bovis and M. avium paratuberculosis (82). Uninfected animals immunized with GMM also developed GMM-specific CD1b-restricted T-cells, which persisted 4 months after the last immunization (83).

Studies performed in CD1 transgenic mice showed lipidspecific T-cells upon immunization with M. tuberculosis lipids or infected with $M$. tuberculosis (84).

Several studies investigated the response of human T-cells to stimulation with mycobacterial lipids ex vivo. Using this approach, T-cells specific for the mycobacterial antigens GroMM (22), GMM (85), SGL (26), MA (74), and MPM (30) were identified. In several cases, these T-cells were detected only in tuberculosis patients and not in healthy individuals, indicating that priming with lipid antigens occurs during infection.

A series of important immunological questions on the role of lipid-specific T-cells in tuberculosis remain to be answered. Firstly, most of the studies were performed with established T-cell clones using different cellular assays including cell proliferation, IFN $\gamma$ release, and cell cytotoxicity. These assays detect protective anti-microbial capacities and indicate potential anti-microbial protective effects of these cells. These studies should be complemented with the functional analysis of T-cells freshly isolated from tuberculosis patients and possibly by in vivo studies using CD1 transgenic mice. Secondly, the mechanisms of lipid-specific T-cell memory generation remain unknown. The experimental data showing absence of mycobacterial lipid-specific T-cells in non-infected individuals supports that naïve T-cells are primed by a specific antigen and expand in vivo. Whether these cells persist for a long period of time and rapidly expand upon challenge with the antigen is not clear. These issues are of paramount importance to understand the possible use of lipid antigens as novel sub-unit anti-mycobacterial vaccines. Thirdly, the tissue-specific expression of CD1 proteins might represent a limitation to the protective activity of CD1-restricted T-cells. Macrophages are the cells harboring Mycobacteria during infection and do not express detectable levels of CD1 molecules. Therefore, these cells might be invisible to lipid-specific T-cells, thus reducing their potential protective role. Another important issue is whether CD1-restricted T-cells massively migrate to infected tissues, mostly the lung, and therefore are rare in circulating blood. The accumulation of lipidspecific T-cells in the lung of tuberculosis patients has not been properly investigated yet.

The second population of lipid-specific T-cells is represented by iNKT cells, which are innate-like T-cells. These cells are constantly activated by a variety of self- and microbial antigens and show a phenotype of pre-activate cells. They contain in their cytoplasm preformed cytokines mRNA, including IFN $\gamma$ mRNA. They readily secrete these cytokines upon antigen recognition at levels that are up to 200-fold higher than those of naïve peptide-specific T-cells $(86,87)$. They also rapidly induce DC maturation, which in turn facilitates priming of $\mathrm{CD}^{+}$cytotoxic T-cells (88). Considering that this latter T-cell population is relevant in protection during mycobacterial infections (89), iNKT cell engagement might be also important for protection.

In vivo studies conducted in mice also showed that iNKT are activated during mycobacterial infections. Following BCG infection, there is an increase of iNKT cells in the lung that show signs of activation (90). iNKT cells were assumed to be important in development of lung granuloma following infection (90-92). Instead a series of studies performed using CD1d-deficient mice (lacking all types of CD1d-restricted T-cells) or J 118 -deficient animals (lacking mainly iNKT cells), did not show relevant difference in the mycobacterial colony forming units in the lung, nor in the survival of infected animals as compared to wild type mice (93-96).

Overall these studies showed that iNKT cells do not have an impact on chronic infection in mice and suggest that they are not involved in direct protective roles during tuberculosis. Thus, the potentially protective functions of iNKT cells, if any, may be present only in the early acute phases of microbial infections and be neglectable in the natural course of prolonged chronic infections such as tuberculosis.

Studies conducted in humans are observational and are limited to the numbers, phenotype, and ex vivo function of iNKT cells isolated from peripheral blood. None of these investigations supported an important role of iNKT cells in tuberculosis, although reduction in their number and phenotype has been observed in patients with active tuberculosis (97-99).

\section{CONCLUSION}

From the overview of the studies reported here, there are increasing evidences of the relevance of the immune response elicited by mycobacterial lipids. The identification of lipid molecules essential 
for bacterial virulence together with the absence of functional CD1 polymorphisms is the basis for vaccine development. There is therefore increasing hope that the inclusion of lipid antigens in new vaccine formulations would lead to a successful vaccination against tuberculosis.

\section{ACKNOWLEDGMENTS}

European Union FP7 NEWTBVAC program, Swiss National Foundation Grant 310030_149571, A-STAR Australian NHMRC joint grant No. 12/1/82/24/6277, and BMRC-SERC grant No. 112 1480006 .

\section{REFERENCES}

1. Porcelli S, Morita CT, Brenner MB. CDlb restricts the response of human CD4-8- T lymphocytes to a microbial antigen. Nature (1992) 360(6404):593-7. doi:10.1038/360593a0

2. Porcelli SA. The CD1 family: a third lineage of antigen-presenting molecules. Adv Immunol (1995) 59:1-98. doi:10.1016/S0065-2776(08)60629-X

3. Karakousis PC, Bishai WR, Dorman SE. Mycobacterium tuberculosis cell envelope lipids and the host immune response. Cell Microbiol (2004) 6(2):105-16. doi:10.1046/j.1462-5822.2003.00351.x

4. Neyrolles O, Guilhot C. Recent advances in deciphering the contribution of Mycobacterium tuberculosis lipids to pathogenesis. Tuberculosis (Edinb) (2011) 91(3):187-95. doi:10.1016/j.tube.2011.01.002

5. Cox JS, Chen B, McNeil M, Jacobs WR Jr. Complex lipid determines tissuespecific replication of Mycobacterium tuberculosis in mice. Nature (1999) 402(6757):79-83. doi:10.1038/47042

6. Cambier CJ, Takaki KK, Larson RP, Hernandez RE, Tobin DM, Urdahl KB, et al. Mycobacteria manipulate macrophage recruitment through coordinated use of membrane lipids. Nature (2014) 505(7482):218-22. doi:10.1038/nature12799

7. Ham H, Sreelatha A, Orth K. Manipulation of host membranes by bacterial effectors. Nat Rev Microbiol (2011) 9(9):635-46. doi:10.1038/nrmicro2602

8. De Libero G, Mori L. Recognition of lipid antigens by T cells. Nat Rev Immunol (2005) 5(6):485-96. doi:10.1038/nri1631

9. Sugita M, Grant EP, Van Donselaar E, Hsu VW, Rogers RA, Peters PJ, et al. Separate pathways for antigen presentation by CD1 molecules. Immunity (1999) 11(6):743-52. doi:10.1016/S1074-7613(00)80148-X

10. Barral DC, Cavallari M, McCormick PJ, Garg S, Magee AI, Bonifacino JS, et al. CDla and MHC class I follow a similar endocytic recycling pathway. Traffic (2008) 9(9):1446-57. doi:10.1111/j.1600-0854.2008.00781.x

11. Zajonc DM, Elsliger MA, Teyton L, Wilson IA. Crystal structure of CD1a in complex with a sulfatide self antigen at a resolution of 2.15 A. Nat Immunol (2003) 4(8):808-15. doi:10.1038/ni948

12. Zajonc DM, Crispin MD, Bowden TA, Young DC, Cheng TY, Hu J, et al. Molecular mechanism of lipopeptide presentation by CD1a. Immunity (2005) 22(2):209-19. doi:10.1016/j.immuni.2004.12.009

13. Moody DB, Young DC, Cheng TY, Rosat JP, Roura-Mir C, O’Connor PB, et al. $\mathrm{T}$ cell activation by lipopeptide antigens. Science (2004) 303(5657):527-31. doi:10.1126/science.1089353

14. Gadola SD, Zaccai NR, Harlos K, Shepherd D, Castro-Palomino JC, Ritter G, et al. Structure of human CD1b with bound ligands at $2.3 \mathrm{~A}$, a maze for alkyl chains. Nat Immunol (2002) 3(8):721-6. doi:10.1038/ni821

15. Batuwangala T, Shepherd D, Gadola SD, Gibson KJ, Zaccai NR, Fersht AR, et al. The crystal structure of human CD1b with a bound bacterial glycolipid. J Immunol (2004) 172(4):2382-8. doi:10.4049/jimmunol.172.4.2382

16. Garcia-Alles LF, Versluis K, Maveyraud L, Vallina AT, Sansano S, Bello NF, et al. Endogenous phosphatidylcholine and a long spacer ligand stabilize the lipidbinding groove of CD1b. EMBOJ (2006) 25(15):3684-92. doi:10.1038/sj.emboj. 7601244

17. Garcia-Alles LF, Collmann A, Versluis C, Lindner B, Guiard J, Maveyraud L, et al. Structural reorganization of the antigen-binding groove of human CD1b for presentation of mycobacterial sulfoglycolipids. Proc Natl Acad Sci U S A (2011) 108(43):17755-60. doi:10.1073/pnas.1110118108

18. De Libero G, Mori L. Novel insights into lipid antigen presentation. Trends Immunol (2012) 33(3):103-11. doi:10.1016/j.it.2012.01.005

19. Beckman EM, Porcelli SA, Morita CT, Behar SM, Furlong ST, Brenner MB. Recognition of a lipid antigen by CD1-restricted alpha beta+ T cells. Nature (1994) 372(6507):691-4. doi:10.1038/372691a0
20. Moody DB, Reinhold BB, Guy MR, Beckman EM, Frederique DE, Furlong ST, et al. Structural requirements for glycolipid antigen recognition by CD1brestricted T cells. Science (1997) 278(5336):283-6. doi:10.1126/science.278. 5336.283

21. Moody DB, Guy MR, Grant E, Cheng TY, Brenner MB, Besra GS, et al. CD1bmediated $\mathrm{T}$ cell recognition of a glycolipid antigen generated from mycobacterial lipid and host carbohydrate during infection. J Exp Med (2000) 192(7):965-76. doi:10.1084/jem.192.7.965

22. Layre E, Collmann A, Bastian M, Mariotti S, Czaplicki J, Prandi J, et al. Mycolic acids constitute a scaffold for mycobacterial lipid antigens stimulating CD1restricted T cells. Chem Biol (2009) 16(1):82-92. doi:10.1016/j.chembiol.2008. 11.008

23. Sieling PA, Chatterjee D, Porcelli SA, Prigozy TI, Mazzaccaro RJ, Soriano T, et al. CD1-restricted T cell recognition of microbial lipoglycan antigens. Science (1995) 269(5221):227-30. doi:10.1126/science.7542404

24. Ernst WA, Maher J, Cho S, Niazi KR, Chatterjee D, Moody DB, et al. Molecular interaction of CD1b with lipoglycan antigens. Immunity (1998) 8(3):331-40. doi:10.1016/S1074-7613(00)80538-5

25. De la Salle H, Mariotti S, Angenieux C, Gilleron M, Garcia-Alles LF, Malm D, et al. Assistance of microbial glycolipid antigen processing by CD1e. Science (2005) 310(5752):1321-4. doi:10.1126/science.1115301

26. Gilleron M, Stenger S, Mazorra Z, Wittke F, Mariotti S, Bohmer G, et al. Diacylated sulfoglycolipids are novel mycobacterial antigens stimulating CD1restricted T cells during infection with Mycobacterium tuberculosis. J Exp Med (2004) 199(5):649-59. doi:10.1084/jem.20031097

27. Goren MB. Immunoreactive substances of mycobacteria. Am Rev Respir Dis (1982) 125(3 Pt 2):50-69.

28. Rousseau C, Turner OC, Rush E, Bordat Y, Sirakova TD, Kolattukudy PE, et al. Sulfolipid deficiency does not affect the virulence of Mycobacterium tuberculosis H37Rv in mice and guinea pigs. Infect Immun (2003) 71(8):4684-90. doi:10.1128/IAI.71.8.4684-4690.2003

29. Scharf L, Li NS, Hawk AJ, Garzon D, Zhang T, Fox LM, et al. The 2.5 A structure of CD1c in complex with a mycobacterial lipid reveals an open groove ideally suited for diverse antigen presentation. Immunity (2010) 33(6):853-62. doi:10.1016/j.immuni.2010.11.026

30. Moody DB, Ulrichs T, Muhlecker W, Young DC, Gurcha SS, Grant E, et al. CD1c-mediated T-cell recognition of isoprenoid glycolipids in Mycobacterium tuberculosis infection. Nature (2000) 404(6780):884-8. doi:10.1038/35009119

31. Shamshiev A, Gober HJ, Donda A, Mazorra Z, Mori L, De Libero G. Presentation of the same glycolipid by different CD1 molecules. J Exp Med (2002) 195(8):1013-21. doi:10.1084/jem.20011963

32. Van Rhijn I, Young DC, De Jong A, Vazquez J, Cheng TY, Talekar R, et al. CD1c bypasses lysosomes to present a lipopeptide antigen with 12 amino acids. J Exp Med (2009) 206(6):1409-22. doi:10.1084/jem.20082480

33. Faure F, Jitsukawa S, Miossec C, Hercend T. CD1c as a target recognition structure for human $\mathrm{T}$ lymphocytes: analysis with peripheral blood gamma/delta cells. Eur J Immunol (1990) 20(3):703-6. doi:10.1002/eji.1830200336

34. Spada FM, Grant EP, Peters PJ, Sugita M, Melian A, Leslie DS, et al. Selfrecognition of CD1 by gamma/delta T cells: implications for innate immunity. J Exp Med (2000) 191(6):937-48. doi:10.1084/jem.191.6.937

35. Lepore M, De Lalla C, Ramanjaneyulu GS, Gsellinger H, Consonni M, Garavaglia $\mathrm{C}$, et al. A novel self-lipid antigen targets human $\mathrm{T}$ cells against $\mathrm{CD} 1 \mathrm{c}+$ leukaemias. J Exp Med (2014) (in press).

36. Matsunaga I, Bhatt A, Young DC, Cheng TY, Eyles SJ, Besra GS, et al. Mycobacterium tuberculosis pks12 produces a novel polyketide presented by CD1c to T cells. J Exp Med (2004) 200(12):1559-69. doi:10.1084/jem.20041429

37. De Jong A, Arce EC, Cheng TY, Van Summeren RP, Feringa BL, Dudkin V, et al. CD1c presentation of synthetic glycolipid antigens with foreign alkyl branching motifs. Chem Biol (2007) 14(11):1232-42. doi:10.1016/j.chembiol.2007.09.010

38. De Libero G, Mori L. The easy virtue of CD1c. Immunity (2010) 33(6):831-3. doi:10.1016/j.immuni.2010.12.001

39. Borg NA, Wun KS, Kjer-Nielsen L, Wilce MC, Pellicci DG, Koh R, et al. CD1dlipid-antigen recognition by the semi-invariant NKT T-cell receptor. Nature (2007) 448(7149):44-9. doi:10.1038/nature05907

40. Patel O, Pellicci DG, Gras S, Sandoval-Romero ML, Uldrich AP, Mallevaey T, et al. Recognition of CD1d-sulfatide mediated by a type II natural killer T cell antigen receptor. Nat Immunol (2012) 13(9):857-63. doi:10.1038/ni.2372

41. Girardi E, Maricic I, Wang J, Mac TT, Iyer P, Kumar V, et al. Type II natural killer $\mathrm{T}$ cells use features of both innate-like and conventional $\mathrm{T}$ cells to recognize sulfatide self antigens. Nat Immunol (2012) 13(9):851-6. doi:10.1038/ni.2371 
42. Rossjohn J, Pellicci DG, Patel O, Gapin L, Godfrey DI. Recognition of CD1d-restricted antigens by natural killer T cells. Nat Rev Immunol (2012) 12(12):845-57. doi:10.1038/nri3328

43. Zajonc DM, Cantu C III, Mattner J, Zhou D, Savage PB, Bendelac A, et al. Structure and function of a potent agonist for the semi-invariant natural killer $\mathrm{T}$ cell receptor. Nat Immunol (2005) 6(8):810-8. doi:10.1038/ni1224

44. Jayawardena-Wolf J, Benlagha K, Chiu YH, Mehr R, Bendelac A. CDld endosomal trafficking is independently regulated by an intrinsic CD1d-encoded tyrosine motif and by the invariant chain. Immunity (2001) 15(6):897-908. doi:10.1016/S1074-7613(01)00240-0

45. Sugita M, Cao X, Watts GF, Rogers RA, Bonifacino JS, Brenner MB. Failure of trafficking and antigen presentation by CD1 in AP-3-deficient cells. Immunity (2002) 16(5):697-706. doi:10.1016/S1074-7613(02)00311-4

46. Cernadas M, Sugita M, Van der Wel N, Cao X, Gumperz JE, Maltsev S, et al. Lysosomal localization of murine CD1d mediated by AP-3 is necessary for NK T cell development. J Immunol (2003) 171(8):4149-55. doi:10.4049/jimmunol. 171.8.4149

47. Lin Y, Roberts TJ, Spence PM, Brutkiewicz RR. Reduction in CD1d expression on dendritic cells and macrophages by an acute virus infection. J Leukoc Biol (2005) 77(2):151-8. doi:10.1189/jlb.0704399

48. Sanchez DJ, Gumperz JE, Ganem D. Regulation of CD1d expression and function by a herpesvirus infection. J Clin Invest (2005) 115(5):1369-78. doi:10.1172/JCI24041

49. Yuan W, Dasgupta A, Cresswell P. Herpes simplex virus evades natural killer T cell recognition by suppressing CD1d recycling. Nat Immunol (2006) 7(8):835-42. doi:10.1038/ni1364

50. Berntman E, Rolf J, Johansson C, Anderson P, Cardell SL. The role of CD1drestricted NK T lymphocytes in the immune response to oral infection with Salmonella typhimurium. Eur J Immunol (2005) 35(7):2100-9. doi:10.1002/eji. 200425846

51. Skold M, Behar SM. Role of CD1d-restricted NKT cells in microbial immunity. Infect Immun (2003) 71(10):5447-55. doi:10.1128/IAI.71.10.5447-5455.2003

52. Mariotti S, Teloni R, Iona E, Fattorini L, Romagnoli G, Gagliardi MC, et al. Mycobacterium tuberculosis diverts alpha interferon-induced monocyte differentiation from dendritic cells into immunoprivileged macrophage-like host cells. Infect Immun (2004) 72(8):4385-92. doi:10.1128/IAI.72.8.4385-4392.2004

53. Gagliardi MC, Lemassu A, Teloni R, Mariotti S, Sargentini V, Pardini M, et al. Cell wall-associated alpha-glucan is instrumental for Mycobacterium tuberculosis to block CD1 molecule expression and disable the function of dendritic cell derived from infected monocyte. Cell Microbiol (2007) 9(8):2081-92. doi:10.1111/j.1462-5822.2007.00940.x

54. Kawano T, Cui J, Koezuka Y, Toura I, Kaneko Y, Motoki K, et al. CD1d-restricted and TCR-mediated activation of valpha14 NKT cells by glycosylceramides. Science (1997) 278(5343):1626-9. doi:10.1126/science.278.5343.1626

55. Gumperz JE, Roy C, Makowska A, Lum D, Sugita M, Podrebarac T, et al. Murine CD1d-restricted T cell recognition of cellular lipids. Immunity (2000) 12(2):211-21. doi:10.1016/S1074-7613(00)80174-0

56. Fox LM, Cox DG, Lockridge JL, Wang X, Chen X, Scharf L, et al. Recognition of lyso-phospholipids by human natural killer T lymphocytes. PLoS Biol (2009) 7(10):e1000228. doi:10.1371/journal.pbio.1000228

57. Facciotti F, Ramanjaneyulu GS, Lepore M, Sansano S, Cavallari M, Kistowska $\mathrm{M}$, et al. Peroxisome-derived lipids are self antigens that stimulate invariant natural killer T cells in the thymus. Nat Immunol (2012) 13(5):474-80. doi:10.1038/ni.2245

58. Fischer K, Scotet E, Niemeyer M, Koebernick H, Zerrahn J, Maillet S, et al. Mycobacterial phosphatidylinositol mannoside is a natural antigen for CD1drestricted T cells. Proc Natl Acad Sci U S A (2004) 101(29):10685-90. doi:10. 1073/pnas.0403787101

59. Kinjo Y, Tupin E, Wu D, Fujio M, Garcia-Navarro R, Benhnia MR, et al. Natural killer $\mathrm{T}$ cells recognize diacylglycerol antigens from pathogenic bacteria. Nat Immunol (2006) 7(9):978-86. doi:10.1038/ni1380

60. Kinjo Y, Illarionov P, Vela JL, Pei B, Girardi E, Li X, et al. Invariant natural killer T cells recognize glycolipids from pathogenic Gram-positive bacteria. Nat Immunol (2011) 12(10):966-74. doi:10.1038/ni.2096

61. Kinjo Y, Pei B, Bufali S, Raju R, Richardson SK, Imamura M, et al. Natural Sphingomonas glycolipids vary greatly in their ability to activate natural killer T cells. Chem Biol (2008) 15(7):654-64. doi:10.1016/j.chembiol.2008.05.012
62. Amprey JL, Im JS, Turco SJ, Murray HW, Illarionov PA, Besra GS, et al. A subset of liver NK T cells is activated during Leishmania donovani infection by CD1d-bound lipophosphoglycan. J Exp Med (2004) 200(7):895-904. doi:10.1084/jem.20040704

63. De Libero G, Moran AP, Gober H-J, Rossy E, Shamshiev A, Chelnokova O, et al. Bacterial infections promote $\mathrm{T}$ cell recognition of self-glycolipids. Immunity (2005) 22:763-72. doi:10.1016/j.immuni.2005.04.013

64. Paget C, Mallevaey T, Speak AO, Torres D, Fontaine J, Sheehan KC, et al. Activation of invariant NKT cells by toll-like receptor 9-stimulated dendritic cells requires type I interferon and charged glycosphingolipids. Immunity (2007) 27(4):597-609. doi:10.1016/j.immuni.2007.08.017

65. Salio M, Speak AO, Shepherd D, Polzella P, Illarionov PA, Veerapen N, et al. Modulation of human natural killer T cell ligands on TLR-mediated antigenpresenting cell activation. Proc Natl Acad Sci U S A (2007) 104(51):20490-5. doi:10.1073/pnas.0710145104

66. Tatituri RVV, Watts GFM, Bhowruth V, Barton N, Rothchild A, Hsu F-F, et al. Recognition of microbial and mammalian phospholipid antigens by NKT cells with diverse tcrs. Proc Natl Acad Sci U S A (2013) 110(5):1827-32. doi:10.1073/pnas.1220601110

67. Angenieux C, Salamero J, Fricker D, Cazenave JP, Goud B, Hanau D, et al. Characterization of CD1e, a third type of CD1 molecule expressed in dendritic cells. J Biol Chem (2000) 275(48):37757-64. doi:10.1074/jbc.M007082200

68. Angenieux C, Fraisier V, Maitre B, Racine V, Van der Wel N, Fricker D, et al. The cellular pathway of CD1e in immature and maturing dendritic cells. Traffic (2005) 6(4):286-302. doi:10.1111/j.1600-0854.2005.00272.x

69. Maitre B, Angenieux C, Salamero J, Hanau D, Fricker D, Signorino F, et al. Control of the intracellular pathway of CD1e. Traffic (2008) 9(4):431-45. doi:10.1111/j.1600-0854.2008.00707.x

70. Maitre B, Angenieux C, Wurtz V, Layre E, Gilleron M, Collmann A, et al. The assembly of CDle is controlled by an N-terminal propeptide which is processed in endosomal compartments. Biochem J (2009) 419(3):661-8. doi:10.1042/BJ20082204

71. Bushmarina N, Tourne S, Giacometti G, Signorino-Gelo F, Garcia-Alles LF, Cazenave JP, et al. Increased flexibility and liposome-binding capacity of CDle at endosomal pH. FEBS J (2011) 278(12):2022-33. doi:10.1111/j.1742-4658. 2011.08118.x

72. Garcia-Alles LF, Giacometti G, Versluis C, Maveyraud L, De Paepe D, Guiard J, et al. Crystal structure of human CD1e reveals a groove suited for lipid-exchange processes. Proc Natl Acad Sci U S A (2011) 108(32):13230-5. doi:10.1073/pnas. 1105627108

73. Facciotti F, Cavallari M, Angenieux C, Garcia-Alles LF, Signorino-Gelo F, Angman L, et al. Fine tuning by human CD1e of lipid-specific immune responses. Proc Natl Acad Sci U S A (2011) 108(34):14228-33. doi:10.1073/pnas. 1108809108

74. Montamat-Sicotte DJ, Millington KA, Willcox CR, Hingley-Wilson S, Hackforth S, Innes J, et al. A mycolic acid-specific CD1-restricted T cell population contributes to acute and memory immune responses in human tuberculosis infection. J Clin Invest (2011) 121(6):2493-503. doi:10.1172/JCI46216

75. Fujii S, Shimizu K, Smith C, Bonifaz L, Steinman RM. Activation of natural killer $\mathrm{T}$ cells by alpha-galactosylceramide rapidly induces the full maturation of dendritic cells in vivo and thereby acts as an adjuvant for combined CD4 and CD8 T cell immunity to a coadministered protein. J Exp Med (2003) 198(2):267-79. doi:10.1084/jem.20030324

76. Van Rhijn I, Kasmar A, De Jong A, Gras S, Bhati M, Doorenspleet ME, et al. A conserved human $\mathrm{T}$ cell population targets mycobacterial antigens presented by CD1b. Nat Immunol (2013) 14(7):706-13. doi:10.1038/ni.2630

77. Van Rhijn I, Gherardin NA, Kasmar A, De Jager W, Pellicci DG, Kostenko L, et al. TCR bias and affinity define two compartments of the CDlb-glycolipid-specific T cell repertoire. J Immunol (2014) 192(9):4054-60. doi:10.4049/jimmunol. 1400158

78. Ly D, Kasmar AG, Cheng TY, De Jong A, Huang S, Roy S, et al. CD1c tetramers detect ex vivo $T$ cell responses to processed phosphomycoketide antigens. J Exp Med (2013) 210(4):729-41. doi:10.1084/jem.20120624

79. Hiromatsu K, Dascher CC, Leclair KP, Sugita M, Furlong ST, Brenner MB, et al. Induction of CD1-restricted immune responses in guinea pigs by immunization with mycobacterial lipid antigens. J Immunol (2002) 169(1):330-9. doi:10.4049/ jimmunol.169.1.330 
80. Watanabe Y, Watari E, Matsunaga I, Hiromatsu K, Dascher CC, Kawashima $\mathrm{T}$, et al. BCG vaccine elicits both T-cell mediated and humoral immune responses directed against mycobacterial lipid components. Vaccine (2006) 24(29-30):5700-7. doi:10.1016/j.vaccine.2006.04.049

81. Dascher CC, Hiromatsu K, Xiong X, Morehouse C, Watts G, Liu G, et al. Immunization with a mycobacterial lipid vaccine improves pulmonary pathology in the guinea pig model of tuberculosis. Int Immunol (2003) 15(8):915-25. doi:10.1093/intimm/dxg091

82. Van Rhijn I, Nguyen TK, Michel A, Cooper D, Govaerts M, Cheng TY, et al. Low cross-reactivity of T-cell responses against lipids from Mycobacterium bovis and M. avium paratuberculosis during natural infection. Eur J Immunol (2009) 39(11):3031-41. doi:10.1002/eji.200939619

83. Nguyen TK, Koets AP, Santema WJ, Van Eden W, Rutten VP, Van Rhijn I. The mycobacterial glycolipid glucose monomycolate induces a memory $\mathrm{T}$ cell response comparable to a model protein antigen and no $\mathrm{B}$ cell response upon experimental vaccination of cattle. Vaccine (2009) 27(35):4818-25. doi:10.1016/ j.vaccine.2009.05.078

84. Felio K, Nguyen H, Dascher CC, Choi HJ, Li S, Zimmer MI, et al. CD1-restricted adaptive immune responses to mycobacteria in human group $1 \mathrm{CD} 1$ transgenic mice. J Exp Med (2009) 206(11):2497-509. doi:10.1084/jem.20090898

85. Ulrichs T, Moody DB, Grant E, Kaufmann SH, Porcelli SA. T-cell responses to CD1-presented lipid antigens in humans with Mycobacterium tuberculosis infection. Infect Immun (2003) 71(6):3076-87. doi:10.1128/IAI.71.6.3076-3087. 2003

86. Stetson DB, Mohrs M, Reinhardt RL, Baron JL, Wang ZE, Gapin L, et al. Constitutive cytokine mRNAs mark natural killer (NK) and NK T cells poised for rapid effector function. J Exp Med (2003) 198(7):1069-76. doi:10.1084/jem. 20030630

87. Matsuda JL, Gapin L, Baron JL, Sidobre S, Stetson DB, Mohrs M, et al. Mouse V alpha 14i natural killer T cells are resistant to cytokine polarization in vivo. Proc Natl Acad Sci U S A (2003) 100(14):8395-400. doi:10.1073/pnas.1332805100

88. Hermans IF, Silk JD, Gileadi U, Salio M, Mathew B, Ritter G, et al. NKT cells enhance CD4+ and CD8+ T cell responses to soluble antigen in vivo through direct interaction with dendritic cells. J Immunol (2003) 171(10):5140-7. doi:10.4049/jimmunol.171.10.5140

89. Winau F, Weber S, Sad S, De Diego J, Hoops SL, Breiden B, et al. Apoptotic vesicles crossprime CD8 T cells and protect against tuberculosis. Immunity (2006) 24(1):105-17. doi:10.1016/j.immuni.2005.12.001

90. Dieli F, Taniguchi M, Kronenberg M, Sidobre S, Ivanyi J, Fattorini L, et al. An anti-inflammatory role for $\mathrm{V}$ alpha $14 \mathrm{NK} \mathrm{T}$ cells in Mycobacterium bovis bacillus Calmette-Guerin-infected mice. J Immunol (2003) 171(4):1961-8. doi:10.4049/jimmunol.171.4.1961

91. Ryll R, Watanabe K, Fujiwara N, Takimoto H, Hasunuma R, Kumazawa Y, et al. Mycobacterial cord factor, but not sulfolipid, causes depletion of NKT cells and upregulation of CD1d1 on murine macrophages. Microbes Infect (2001) 3(8):611-9. doi:10.1016/S1286-4579(01)01416-2
92. Guidry TV, Olsen M, Kil KS, Hunter RL Jr, Geng YJ, Actor JK. Failure of CD1D-/- mice to elicit hypersensitive granulomas to mycobacterial cord factor trehalose 6,6'-dimycolate. J Interferon Cytokine Res (2004) 24(6):362-71. doi:10.1089/107999004323142222

93. Behar SM, Dascher CC, Grusby MJ, Wang CR, Brenner MB. Susceptibility of mice deficient in CD1D or TAP1 to infection with Mycobacterium tuberculosis. J Exp Med (1999) 189(12):1973-80. doi:10.1084/jem.189.12.1973

94. Szalay G, Zugel U, Ladel CH, Kaufmann SH. Participation of group 2 CD1 molecules in the control of murine tuberculosis. Microbes Infect (1999) 1(14):1153-7. doi:10.1016/S1286-4579(99)00248-8

95. Sousa AO, Mazzaccaro RJ, Russell RG, Lee FK, Turner OC, Hong S, et al. Relative contributions of distinct MHC class I-dependent cell populations in protection to tuberculosis infection in mice. Proc Natl Acad Sci U S A (2000) 97(8):4204-8. doi:10.1073/pnas.97.8.4204

96. Kawakami K, Kinjo Y, Uezu K, Yara S, Miyagi K, Koguchi Y, et al. Minimal contribution of Valpha14 natural killer T cells to Th1 response and host resistance against mycobacterial infection in mice. Microbiol Immunol (2002) 46(3):207-10. doi:10.1111/j.1348-0421.2002.tb02687.x

97. Snyder-Cappione JE, Nixon DF, Loo CP, Chapman JM, Meiklejohn DA, Melo FF, et al. Individuals with pulmonary tuberculosis have lower levels of circulating CD1d-restricted NKT cells. J Infect Dis (2007) 195(9):1361-4. doi:10.1086/ 513567

98. Im JS, Kang TJ, Lee SB, Kim CH, Lee SH, Venkataswamy MM, et al. Alteration of the relative levels of inkt cell subsets is associated with chronic mycobacterial infections. Clin Immunol (2008) 127(2):214-24. doi:10.1016/j.clim.2007.12.005

99. Montoya CJ, Catano JC, Ramirez Z, Rugeles MT, Wilson SB, Landay AL. Invariant NKT cells from HIV-1 or Mycobacterium tuberculosis-infected patients express an activated phenotype. Clin Immunol (2008) 127(1):1-6. doi:10.1016/j.clim. 2007.12.006

Conflict of Interest Statement: The authors declare that the research was conducted in the absence of any commercial or financial relationships that could be construed as a potential conflict of interest.

Received: 17 April 2014; paper pending published: 30 April 2014; accepted: 30 April 2014; published online: 22 May 2014.

Citation: De Libero G and Mori L (2014) The T-cell response to lipid antigens of Mycobacterium tuberculosis. Front. Immunol. 5:219. doi: 10.3389/fimmu.2014.00219 This article was submitted to Microbial Immunology, a section of the journal Frontiers in Immunology.

Copyright $\odot 2014$ De Libero and Mori. This is an open-access article distributed under the terms of the Creative Commons Attribution License (CC BY). The use, distribution or reproduction in other forums is permitted, provided the original author (s) or licensor are credited and that the original publication in this journal is cited, in accordance with accepted academic practice. No use, distribution or reproduction is permitted which does not comply with these terms. 